Instructions for authors, subscriptions and further details:

http://brac.hipatiapress.com

\title{
Intersecciones entre Texto e Imagen: Alexander Kluge y el Tratado Iconográfico \\ Jacobo Sucari ${ }^{1}$
}

1) Departament d'Arts Visuals i Disseny, Facultat de Belles Artes, Universitat de Barcelona

Date of publication: February $3^{\text {rd }}, 2021$

Edition period: October 2020 - February 2021

To cite this article: Sucari, J. (2020). Intersecciones entre Texto e Imagen: Alexander Kluge y el Tratado Iconográfico. Barcelona, Research, Art, Creation, 9(1), pp. 45-58. doi: 10.17583/brac.2021.5364

To link this article: http://dx.doi.org/10.17583/brac.2021.5364

\section{PLEASE SCROLL DOWN FOR ARTICLE}

The terms and conditions of use are related to the Open Journal System and to Creative Commons Attribution License (CC-BY). 
BRAC - Barcelona Research Art Creation. Vol. 9 No. 1, February 2021, pp. $45-58$

\section{Intersections between Text and Image: Alexander Kluge and the Iconographic Treatise}

Jacobo Sucari

Departament d'Arts Visuals i Disseny. Facultat de Belles Artes. Universitat de Barcelona

(Received: 7 June 2020; Accepted: 28 October 2020; Published: 3 February 2021)

\section{Abstract}

There is a field of intersection between text and image that throughout the history of cinema has been configured as a space of subtle architectures where the typographic sign (the letter) and its sound emission (the voice) in conjunction with the image, they form a terrain of new audiovisual grammars, a space for experimentation in the creation of meaning and original associations.

Alexander Kluge's work is undoubtedly a special case in forcing this relationship between the dimensions of text and image, not only because he has dedicated much of his work to both disciplines, that of writer and that of filmmaker, but because in this space of intersection of the written word and the fluorescence of the image, a renewed dialogue emerges around the meaning of history and the always enriching links between the archive, the document, the function of memory and a critical view of the Present.

This article emphasizes the semiotic characteristics of this relationship between text and image in Kluge's work, as well as his peculiar conception of the audiovisual treatise.

Keywords: Kluge, aesthetics of the image, media archaeology, political image, image and writing

2021 Hipatia Press

ISSN: 2014-8992

DOI: $10.17583 /$ brac. 2021.5364

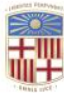

UN IVER S T TAT BARCELONA
Hipatia Press

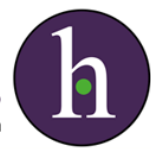


BRAC - Barcelona Research Art Creation. Vol. 9 No. 1, February 2021, pp. 45-58

\section{Intersecciones entre Texto e Imagen: Alexander Kluge y el Tratado Iconográfico}

Jacobo Sucari

Departament d'Arts Visuals i Disseny. Facultat de Belles Artes. Universitat de Barcelona

(Recibido: 7 junio 2020; Aceptado: 28 octubre 2020; Publicado: 3 febrero 2021)

\section{Resumen}

Existe un campo de intersección entre texto e imagen que a lo largo de la historia del cine se ha ido configurando como un espacio de arquitecturas sutiles donde el signo tipográfico (la letra) y su emisión sonora (la voz) en conjunción con la imagen, configuran un terreno de nuevas gramáticas audiovisuales, un espacio de experimentación en la creación de sentido y asociaciones originales.

El trabajo de Alexander Kluge es sin duda un caso especial en el forzamiento de esta relación entre las dimensiones del texto y la imagen, no solo porque haya dedicado gran parte de su trabajo a ambas disciplinas, la de escritor y la de cineasta, sino porque en ese espacio de intersección de la palabra escrita y la fluorescencia de la imagen, aflora un diálogo renovador en torno al sentido de la historia y de los vínculos siempre enriquecedores entre el archivo, el documento, la función de la memoria y una mirada crítica del presente.

En este artículo se hace hincapié en las características semióticas de esta relación entre texto e imagen en el trabajo de Kluge, así como en su peculiar concepción del tratado audiovisual.

Palabras clave: Kluge, estética de la imagen, arqueología de los medios, imagen política, imagen y escritura 


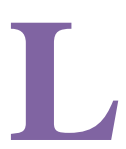

os hermanos Lumière, creadores del cinematógrafo, dudaban de la capacidad de su invento de ir más allá de una curiosidad antropológica y social sobre la imagen como mímesis de lo real. La capacidad de poder observar el movimiento de objetos, de las gentes, observar el paso del tiempo, jugar con la continuidad lineal del tiempo congelando la imagen, acelerándola, invirtiéndola. Eran estas precisamente las razones de fascinación del público.

La magia de su invención se basaba en la manipulación del movimiento de las formas y con ello, en la idea de un tiempo humano capaz de ser medido a través de la plasmación objetiva de la máquina.

Este esplendor sobre la fantasía temporal que desencadenó el cinematógrafo podría parecer más que suficiente de cara a las expectativas del espectador, pero sin embargo el cine quiso ir más allá del registro mimético de lo observable, incorporando la novela y el teatro; para sumarle así a la moción, la emoción que puede sugerir el actor y una narrativa que se desarrolla de manera dramática.

Para quienes entendieron el cine como un nuevo modo de ver, entender y representar lo real a través del ojo multidimensional de la máquina, el dispositivo cinematográfico no era sólo potestad de los narradores de historias vinculados al devenir del teatro, sino que desde otras disciplinas ajenas a la ficción se hacía manifiesta la ansiedad por participar en la construcción de esta nueva mirada, y en ese contexto de experimentación, los músicos no fueron ajenos a la utilización del medio.

Mientras Griffith, en Intolerance (1916) necesitaba de tres horas y media de película para narrar la historia universal de la intolerancia, el grupo Dziga Vertov (1917) en la URSS, comenzó a elaborar un cine cargado de la lógica rítmica de la música. Constituyeron un cine antropológico y político sobre las comunidades campesinas de la Rusia profunda con un ritmo de montaje propio de la instrumentación de la música electroacústica de entonces.

La enorme imantación del cine en sus comienzos atrajo también a arquitectos, pintores, bailarines, gentes de circo. La participación de cada forma tradicional del arte logró imprimir en el cine un sello, una mirada y un ritmo. Sin embargo, la forma ensayo tardó en llegar al audiovisual.

A pesar de la temprana implantación de la literatura en el cine, los prejuicios de muchos escritores respecto de la industria del cine fueron constantes. Como sugiere Pantoja (2007) en un estudio sobre la imagen como nueva forma de escritura: la enorme capacidad de creación de imaginarios que propicia el audiovisual, de sus fórmulas de síntesis emocional y la enorme 
empatía que provoca en el espectador, son características que motivan serios recelos en el ámbito estricto de la circulación del pensamiento. La filosofía junto al ensayo se encontraban mucho más cómodas en la letra y el libro que en manos de la capacidad provocativa de la imagen.

En la Europa de comienzos del siglo XX donde revolución y contrarevolución batallaban en el ámbito cotidiano de la propaganda de masas, la imagen cinematográfica fue considerada por muchos de estos sectores apegados a una cultura tradicional como la punta de lanza de la imposición de un pensamiento único y homogéneo.

Si bien desde la Escuela de Frankfurt, en especial a través de la obra de Walter Benjamin (1940), se auspició una nueva interpretación de este mundo de la imagen técnica a partir del análisis de los cambios que provoca la reproductibilidad técnica, no es menos cierto que Adorno y Horkheimer (1988) vieron en el nacimiento de la industria cultural la semilla de un pensamiento unidimensional en un contexto proto-fascista, auspiciado precisamente por las tecnologías de la comunicación y los medios masivos de penetración cultural. Según cuentan, la actitud de Adorno hacia el cine se basaba en el siguiente apotegma: "Me encanta ir al cine; lo único que me molesta es la imagen en la pantalla" (Maiso, 2004).

Heredero de este pensamiento crítico que quería construir mundo, pero a cuyos protagonistas el avance del nazismo empujó hacia la muerte y el exilio, Alexander Kluge se reconoce también en esa dinámica del pensamiento alemán que en la fuerza de su batalla frente a la barbarie propuso la acción permanente como dinámica vital e intelectual. Un activismo político que se hace explícito a través del texto y de la palabra, pero también capaz de utilizar la imagen en igual dimensión expresiva (Bellour, 2009).

Es Bertold Brecht, uno de los referentes directos del trabajo de Kluge, quien durante su exilio de itinerante nómade con maleta única, recorta fotos, crea álbumes, escribe sutiles pies de foto en un trabajo de apropiación de textos con imágenes de la prensa en lo que se conocerán posteriormente como sus cuadernos del ABC de la Guerra (1938) donde se articulan de manera original ambos lenguajes y donde se pone de manifiesto la capacidad crítica de esta nueva hibridación de pensamiento y documento visual (DidiHuberman, 2008).

Se suele señalar la importancia fundamental que adquieren estas herramientas expresivas de la modernidad en la utilización propagandística de la imagen como forma de estetizar la política por parte del fascismo, frente a la idea de politizar la estética, como manera de reivindicar una nueva praxis en la dimensión del arte político. 
Alexander Kluge formó parte de este club de pensadores excepcionales en el rol de abogado de la Escuela de Frankfurt. Tras su reapertura, luego de los largos años de represión y exilio que provocó el régimen nazi, el joven Kluge trabajó allí en los primeros años de la posguerra como asesor legal y secretario. Como heredero de ese pensar tuvo que lidiar desde entonces con las palabras y textos de Adorno sobre las condiciones y modos de producción del cine en el marco de una industria que, según remarcaba, tendía a una globalización tribal del pensamiento único (Adorno, 2008).

La conjunción original de texto e imagen busca renovar o quizás simplemente poder nombrar un estado de vida en medio de un conflicto donde las palabras muchas veces no llegan. Poner de manifiesto un activismo político que por lo general se hace explícito a través del texto escrito, pero como en Brecht y más tarde en Kluge, se utiliza la imagen como nueva dimensión expresiva desde una didáctica radical en busca de aquella imagen dialéctica relampagueante a la que se refería Benjamin (2005).

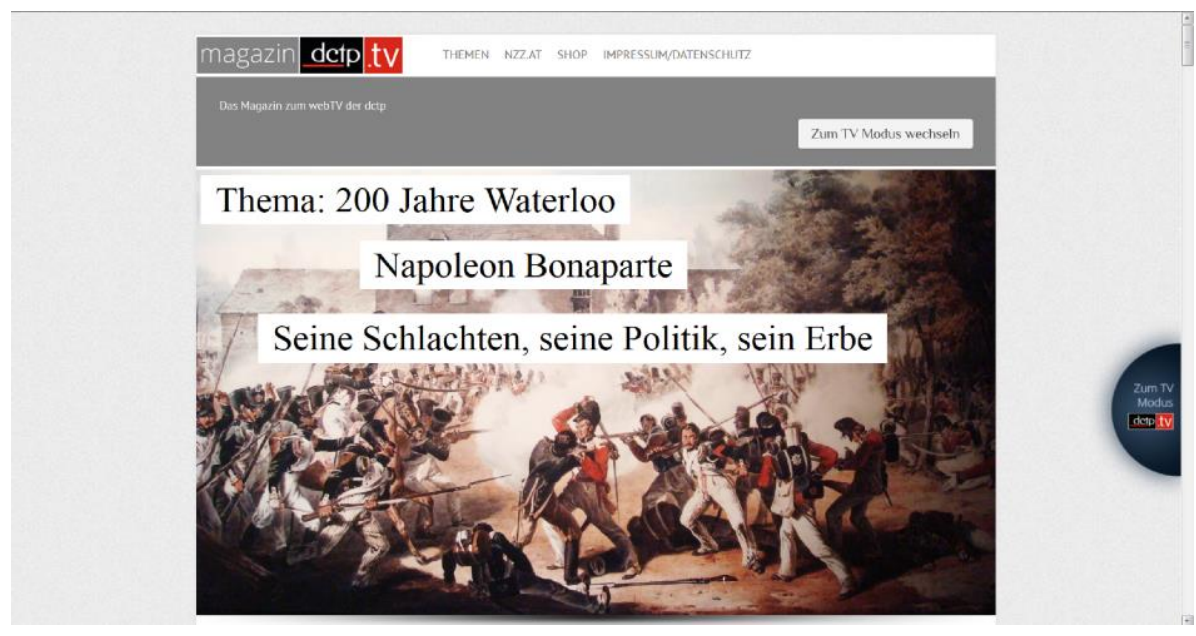

Imagen 1. Kluge, A. (2015). Carátula de programa DCTP/TV, (C) DCTP. https://www.dctp.tv/

\section{La Forma Tratado}

La fructífera carrera audiovisual de Kluge en el contexto de una época de grandes frustraciones en el ámbito de la producción audiovisual contestataria, no deja de llamar la atención. Si uno se pregunta cómo fue capaz el joven abogado Alexander Kluge de articular la construcción audiovisual de su obra a partir de esta síntesis entre tradición y renovación, la primera pista que surge 
viene del ámbito de su profesión como legislador. El documento, como constatador de los hechos de la historia adquiere una importancia fundamental en su obra; y es esta mirada especial sobre el documento y la función del archivo aquello que nos permite acercarnos a su particular idea del funcionamiento de la imagen y el texto, del cine, de la literatura, y de su fusión en la TV.

Es a partir del documento, del uso del archivo, que Kluge dimensiona su relación con la historia y donde recrea una fricción especial entre texto e imagen. El documento es el gran testigo, y el que otorga validez de la existencia de los hechos. La historia es entonces documento, y en la manera en que podamos peinar a contrapelo, decía Benjamin, es decir, en la manera de releer estos documentos de la historia, actualizamos el pasado, variando el orden y la mirada sobre los hechos históricos que configuran el presente.

La obra de Kluge, y en especial el tipo de imagen que recrean sus programas para televisión de los últimos años, son en esencia un acercamiento a las imágenes-documento, pero no desde la mirada del narrador que crea dramas en tres actos categorizados ya por Aristóteles, y que precisa de ese arco que va desde el comienzo hacia un climax y que encuentra una resolución final dramatizada; sino que lo realiza desde la forma del tratado.

Según el diccionario español on-line de Oxford, el tratado se entiende como una "obra escrita que trata extensa y ordenadamente sobre una materia determinada”. A esa obra escrita, Kluge suma el documento-imagen de manera de tensar nuevos acordes en las resonancias de la historia, y en esa idea de espacio de síntesis donde texto e imagen se re-configuran.

Alexander Kluge encuentra en ese espacio, un tiempo, un ritmo que es una modulación del pensamiento buscando nuevo corredores y puertas por las que transitar. De hecho, la definición de tratado del diccionario on line de la RAE nos habla de un "documento en el que se recoge el acuerdo en materia política, económica, social, etc., entre dos estados”. Ese documento es el que Kluge hace hablar en sus programas de televisión, y al que pone en fricción entre dos estados, más bien entre dos estados del ser: el que se configura en cuanto memoria histórica y aquel que se actualiza en el presente a partir de su uso.

En "Tesis de historia de la filosofía" Benjamin (1940) proponía al historiador peinar la historia a contrapelo para percibir nuevas resonancias de los datos de la historia, y Kluge en su trabajo textual y audiovisual, da cabal pie a esta vindicación.

Sin embargo, las características del tratado audiovisual que Kluge aplica, difieren de las formas del ensayo que se ha puesto de manifiesto en el cine y en documental en los últimos años. Obviando las definiciones y referentes 
tradicionales sobre el ensayo, que se pueden rastrear a través de Montaigne como figura fundamental del género, es importante remarcar que la primera persona que construye el ensayo es un yo que desde su centro dispone el mundo. El yo que se expresa en el ensayo, es como el ojo observador de la perspectiva renacentista que asume un punto de vista ideal sobre la res-extensa (el mundo), donde siempre topa con los límites de la polaridad subjetiva/objetiva: el mundo está ahí fuera, el yo lo percibe y lo modula a partir de su relato.

La forma tratado que Kluge adopta deja de lado esta poética del yo y dispone los objetos del mundo de manera que estos sean capaces de constituir un juego de relaciones lógicas. El yo habla y se manifiesta (indefectiblemente) también en el tratado, pero crea distancia, da espacio y tiempo para la interpretación subjetiva del observador, tensa la propia noción de sentido que el documento crea, construye a partir de una serie de silogismos.

Los audiovisuales de no ficción de Kluge para sus programas en televisión se construyen a la manera de tratados lógicos, pero por la propia polisemia de la imagen, los silogismos que articula se parten, se quiebran, y transporta al lector (de texto e imagen) a otros sitios, expandiendo y contradiciendo su eslabón anterior, de manera que la lógica del texto se rompe, o se abre a nuevas interpretaciones.

Cabría analizar esta forma de trabajo mediante ejemplos singulares que de manera insistente se pueden encontrar en el trabajo audiovisual de Kluge, pero no es este el momento para un trabajo de análisis exhaustivo de su método de construcción en la programación que desarrolla su productora de televisión, la DCTP (Development Company for Television Programs), sino de resaltar la propuesta estética y política en su trabajo, y en la particular dimensión que su uso del texto y la imagen provee al conjunto de su obra, mediante una especial forma constructiva.

Es a partir de los años sesenta que el cine de no ficción comenzó a tener grandes ensayistas. Un "cine del yo" que discurre más hacia el oído (desde la palabra) que a la vista (lo fotografiable), esa "forma que piensa", en palabras del profesor Josep M. Català (2000) en referencia a una categoría original que surge mediante el ensayo audiovisual.

El cine de Kluge, muy cercano al desarrollo de "esa forma que piensa", elabora una apuesta estética que ha sabido cimentar en años de trabajo y que propicia un distanciamiento propio del tratado, una forma afín a su propio ritmo y carácter personal. Se construye, a partir de estos parámetros, un mundo creativo personal, pero sin tener como eje el discurso del yo, sino a partir del ello, una tercera persona mediatizada que surge como un relator 
objetivo que se desprende del documento. El documento, esa especie de inconsciente de la historia que aflora en los archivos para revelar momentos desesperados, aunque también para describir tardes de total apatía, y que el paso del tiempo convierte y remueve, de manera que hace posible entendernos y extendernos en el tiempo, en una huella del tiempo que nos interpela y que el documento siempre valida.

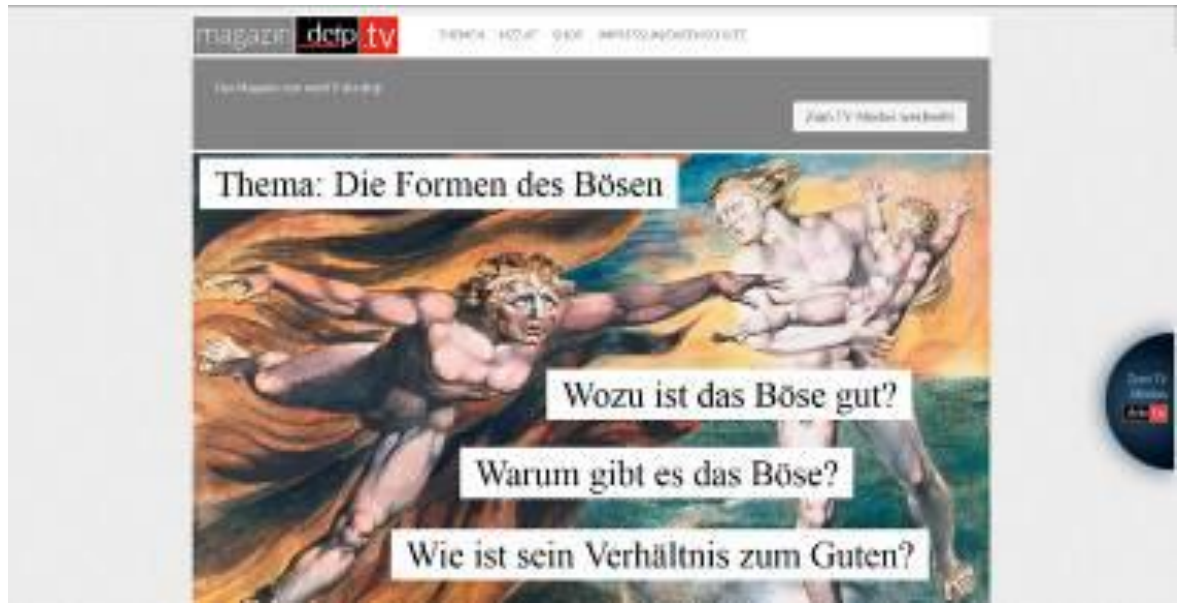

Imagen 2. Kluge, A. (2015). Carátula de programa DCTP/TV, () DCTP. https://www.dctp.tv/

\section{El Editor Audiovisual}

Kluge ha extrapolado para el cine y la TV al editor del mundo del libro, aquel que escoge textos ajenos para publicar según una estética y unos criterios, que crea tendencias y valor de mercado. Pero transforma este personaje del mundo editorial en un editor televisivo, aquel que recoge imágenes dispersas, del mundo del teatro, la ópera, los cómics, la fotografía, las ilustraciones, y que juega con documentos visuales de todo tipo para articular una nueva escritura audiovisual. No es el rol del editor de vídeo, continuador del montador de cine, que domina la técnica de la continuidad dramática y del ritmo, sino un editor que dirige un equipo y que imprime (produce) una programación televisiva.

En este rol de editor audiovisual Kluge monta en 1984, en colaboración con Der Spiegel y la agencia de publicidad japonesa Dentsu, una serie de revistas culturales para distintas cadenas televisivas del nuevo espectro satelital. A partir de 1988, DCTP adquiere una licencia propia de emisión y al 
amparo del nacimiento de estos canales satelitales produce y emite varios programas semanales de cultura. La generación de esferas públicas alternativas a través de los medios de comunicación (especialmente la TV) supone para Kluge crear esferas opuestas a las oficiales, aunque es consciente de que su función quedará limitada a un determinado tipo de experiencias emancipadoras que de poco servirán si el resto de los aspectos de la vida social permanecen inalterables (Ayllón, 2016).

Los programas de TV de la DCTP a los que tuvimos acceso en sus comienzos a través de canales satelitales europeos, provocaban un asombro especial: se disponía como un programa de TV de autor mediante un discurso de rupturas y contrapunto entre textos e imágenes, con la estética del vídeo electrónico (el digital aún no había llegado) donde las líneas argumentales podían ser difusas, complejas, literarias o simplemente asociativas (Alcalá, 2014). Como sugiere Kluge: "Mis ideas pueden ser tan inconexas como se quiera, e incluso puede parecer que se contradicen: basta que con estas ideas aporten un material de reflexión" (2014, p.11)

En momentos en que muchos de los artistas de vídeo abandonaban la estética de las imágenes manipuladas electrónicamente, y también los envejecidos equipos con los que trabajaban, y cuando el mercado de los efectos especiales y los nuevos sintetizadores de imagen se habían deglutido este espacio de experimentación, Kluge asume un lenguaje formal con reminiscencias en la psicodelia de la electrónica de bajo coste. Mediante un trabajo analógico por capas de imágenes y sonidos, como editor de TV Kluge articula sus producciones mediante imágenes conseguidas en el plató, con recortes austeros de chroma kyes (recortes a partir del fondo de color) donde nos presenta catástrofes náuticas mediante barquitos de papel en cubetas de fotógrafo con extraños colores psicodélicos, a la que suma una íntima y clásica música de cámara, junto a textos que atraviesan la imagen, citas a partir de intertítulos, voces en off que recitan poemas líricos, solarizaciones e imágenes de archivo en negativo. Incluso los estudiantes de audiovisuales habían abandonado ya entonces esta estética de plató televisivo y mezcladoras analógicas de imagen y sonido. Y, sin embargo, Kluge logra que los programas de la DCTP sean fascinantes.

En una retrospectiva museística de la obra de Kluge realizada en el 2016 en la ciudad de Barcelona, en el Palau de la Virreina con el título de "Jardines de cooperación" pudimos apreciar el conjunto de su obra como un trabajo que se corrige constantemente, que se escribe y reescribe intentando manifestar la importancia del proceso y el contexto, del montaje como un concepto asociativo, creativo y libre que va más allá del propio material fílmico, que 
deviene un mosaico que no conoce fin. "En Kluge el montaje deviene motor creativo que libera y permite cooperación reflexiva. Sus ensayos fílmicos, en su gran mayoría, son sumas de imágenes, músicas y vocablos en pleno ejercicio de colaboración (Prieto, 2017, p. 2).

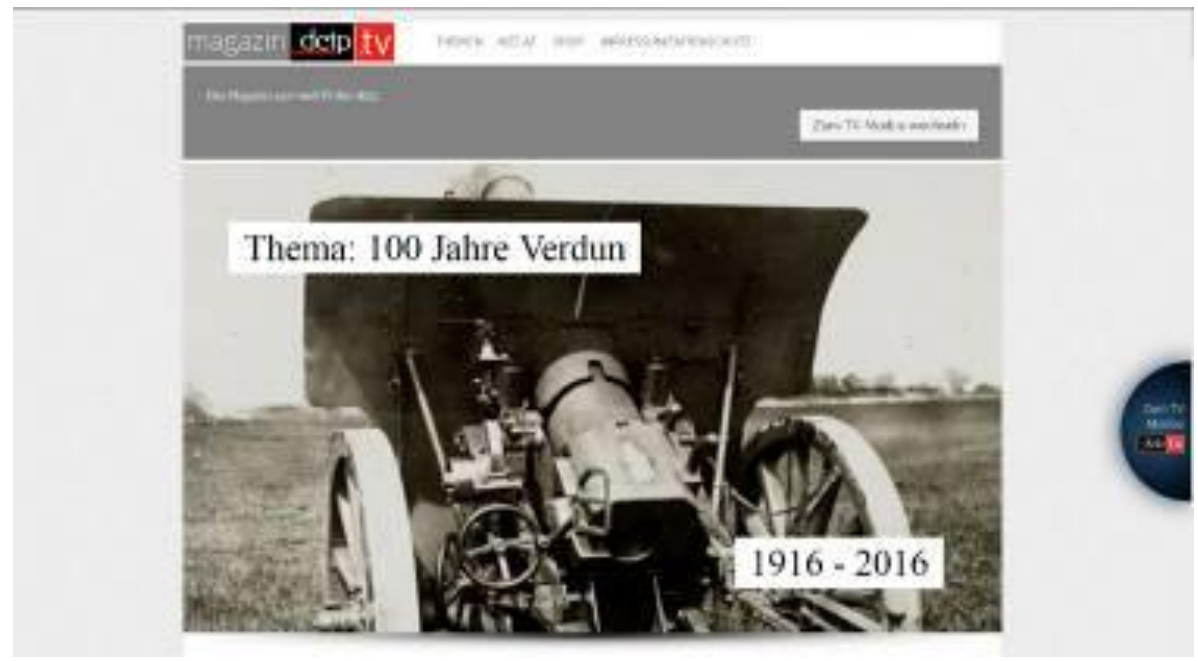

Imagen 3. Kluge, A. (2015). Carátula de programa DCTP/TV, (C DCTP. Recuperado de https://www.dctp.tv/

\section{Texto e Imagen como Recreación de la Historia}

El cineasta Alexander Kluge se constituye como heredero de una amplia tradición del pensamiento alemán, desde el romanticismo de Schiller, al materialismo histórico de Marx y el pensamiento crítico de la Escuela de Frankfurt. En este recorrido por el mundo del pensamiento y el activismo, también incorpora las formas simples de los paneles de Aby Warburg, a quien actualiza en la manera de romper la linealidad de las imágenes, armando nuevas configuraciones audiovisuales como quien confecciona mundos, reconstruyendo la historia del arte en asociaciones complejas, abriendo desde el campo de la imagen, nuevos espacios de pensamiento. Recuperando en esta tarea de vincular tradición y modernidad, a artistas como John Heartfield, un autor de collages de imágenes fijas capaz de elaborar una crítica política descomunal y a la vez de una modernidad desbordante sobre la Alemania nazi, con seguidores contemporáneos de la talla de Hans Haacke y Wodiczko. Encontramos a través de estos artistas y activistas, toda una línea de acción y pensamiento que parece pasarse el testigo a lo largo del siglo $\mathrm{XX}$, 
configurando un acercamiento crítico a la construcción de una memoria histórica, y desde donde se reinterpreta la tensión existente entre texto e imagen.

Es en esta línea de pensamiento y acción donde la tradición crítica encontró un modo de señalar la importancia fundamental que tiene la imagen como herramienta expresiva de la modernidad. Un cosmos de imágenes y pantallas que se constituyen como la base de la industria de la cultura, una industria donde se practica un peligroso laboratorio de consenso social, pero donde a su vez, por el contrario, la imagen del cine y de la tv es capaz de potenciar inéditos imaginarios. Imágenes y sonidos generados desde la resistencia a la comunicación corporativa que a manera de pharmakon (Deleuze, 1968) son el veneno, pero al mismo tiempo, la posibilidad de cura de la enfermedad de la imagen.

Kluge es capaz de recoger el testigo de este enfrentamiento y disponer en el centro de su vasta producción creativa obras que se mueven entre la tradición y la ruptura. Una obra, según él mismo señala, que surge desde el pensamiento a través de los sentimientos. Pensar y sentir como forma de acompañarse y acompañar, de compartir, para no caer en la melancolía intelectual ni en la servidumbre de una élite culta que acaba reproduciendo aquello que critica. La cooperación como camino de creación que crea comunidad.

Un proceso de creación artístico que se apoya en aquello colaborativo y que rompe con los preceptos de la modernidad, aquel dar a ver propio de la fotografía y el documental social, aquel desvelar lo que subyace escondido, para pasar a configurar un nuevo nosotros que se expresa en una comunidad que reflexiona sobre el contenido semántico de una obra siempre en proceso.

En este sentido y apelando a la comunidad, la obra ensayística textual y la producción de imágenes de Kluge, rodea y se zambulle en la comprensión de la esfera pública, en la experiencia productiva y su vinculación con el servicio comunitario. Para Kluge, en la lucha política ya no se trata de contraponer la industria cultural a los acervos románticos de un yo en combate dialéctico y crítico con su entorno, sino en la capacidad de repensar y experienciar lo común desde un ámbito conjunto, compartido, un trabajo que se plasma y da sus frutos en el ámbito de la experiencia. Kluge ha recogido el testigo de una batalla pretérita, continuando una tradición y al tiempo renovándola, modulando una escritura desde la televisión y desde el libro (dicen de él algunos de sus exégetas, que su prosa es fílmica y sus films literarios), una TV de escritura que no niega el texto ni el tiempo de lectura, ni las formas del montaje, ni las capas del sentido audiovisual de la incrustación digital. 
En este trabajo de re-construcción al que se ha dedicado, vale la pena retornar al visionado de las cientos de horas que desde entonces Kluge ha creado para televisión, construyendo un proyecto que está en los márgenes de todas las modas audiovisuales, pero recuperando los pasos de Rosellini, de Pasolini, de Peter Watkings, de muchos quienes plantearon el uso de la TV como una nueva cultura popular, como un compromiso del realizador audiovisual con su comunidad, como una nueva manera de trenzar texto e imagen para construir nuevas formas expresivas.

La operación creativa de Kluge se resume en una apuesta estética y política que rompe con la sumisión realista del documento como validador de la historia, a la vez que apunta críticamente contra la relativización del documento y del valor de testimonio de la imagen según las corrientes posmodernas que han proliferado en los últimos años en el ámbito de los museos y galerías de arte.

El trabajo de Kluge en tanto hombre de letras, comprometido en los últimos años a partir de la programación de la DCTP a la creación de programas para $\mathrm{TV}$, expresa precisamente que, si el texto y la palabra validan y crean la imagen de la historia, la articulación de la imagen en su proceso productivo es capaz de concebir una nueva visión de la historia.

La materia propia del cine, el conjunto de elementos que lo configuran, es decir, la fotografía, el montaje, el sonido, la proyección, la sala donde el espectador contempla, son todos elementos capaces de hacernos ver detalles de la historia que habíamos descuidado; que incluso pueden despertar de su letargo a partir del archivo, en la dinámica constructiva de la máquina en su proceso expresivo.

Retomando las ideas de Vertov, el cine materialista permite comprender que el lenguaje (el medio), crea el sentido de la historia. Desde esta perspectiva, Alexander Kluge nos muestra que la historia hablada o la historia escrita pueden desandar nuevos caminos y que el choque entre texto e imagen es capaz de generar mundos impensados. 


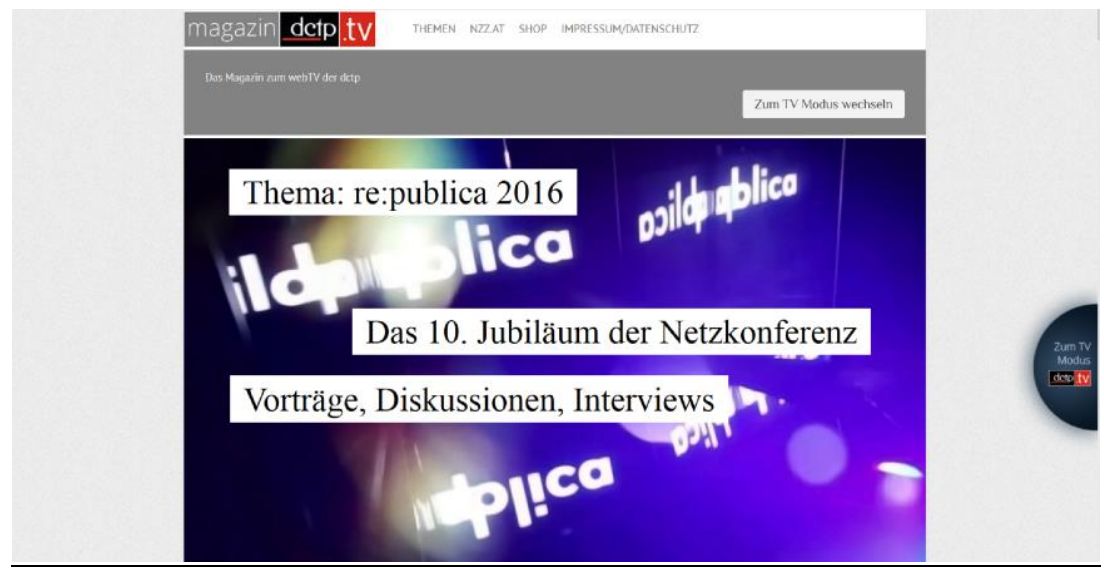

Imagen 4. Kluge, A. (2015). Carátula de programa DCTP/TV, (C) DCTP. https://www.dctp.tv/

\section{Referencias}

Adorno, T. (2008). Crítica de la cultura y sociedad I. Obra completa, 10/1. Ediciones AKAL.

Adorno, T. y Horkheimer, M. (1988). La industria cultural. Iluminismo como mistificación de masas. En Dialéctica del iluminismo. Editorial Sudamericana.

Alcalá, F. (2014). El cine de lo real. En El cine de pensamiento. Formas de la imaginación tecno-estética, (pp 105-119). Aldea Global.

Ayllón, M. (2016). Cine e Industria Cultural. Alexander

Kluge. Constelaciones. Revista De Teoría Crítica, 3(3), 244-256.

Benjamin, W. (1940). Tesis de historia de la filosofía. Edicions De L'ateneu De Benimaclet.

Benjamin, W. (2005). Parque Central. Traducción de Ronald Kay.

Ediciones Metales Pesados. Santiago.

Bellour, R. (2009). Entre imágenes. Ediciones Colihue.

Català, JM. El film-ensayo: la didáctica como una actividad subversiva. Archivos de la Filmoteca, $n^{o}$ 34, febrero 2000, pp. 79-97.

DCTP (Development Company for Television Programs).

Deleuze, G. (1968). Différence et répétition. Presses Universitaires de France. Didi-Huberman, G. (2008). Cuando las imágenes toman posición. Ed. A. Machado Libros.

Kluge, A. (2015). Ataque aéreo a Halberstadt, El 8 de abril de 1945. Ed. A. Machado Libros. 
Maiso-Blasco, J. (2004). La inmediatez quebrada. El cine como escritura audiovisual, de Kugle a Haneke: una tradición adorniana. Binaria, 4. Pantoja Chaves, A. (2007). La imagen como escritura. El discurso visual para La historia. Norba. Revista de Historia. ISSN 0213-375X, Vol. 20, 2007, pp. 185-208.

Prieto, I. (2017). Acompañamientos hacia el mosaico: Alexander Kluge. Revista Campo de Relámpagos.

Jacobo Sucari: Doctor y profesor en el Departament d'Arts Visuals i Disseny, Facultat de Belles Artes, Universitat de Barcelona. Artista visual e investigador.

Email address: jacobosucari@gmail.com

Contact Address: Facultat de Belles Arts, Pau Gargallo 4, 08028 Barcelona. 